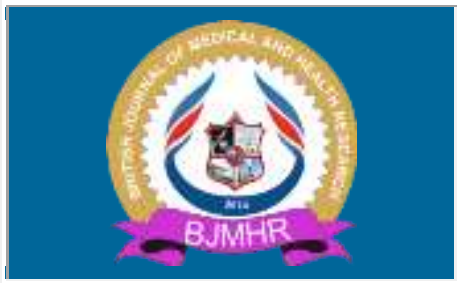

\title{
BJMHR
}

British Journal of Medical and Health Research

Journal home page: www.bjmhr.com

\section{Assessing the Awareness and Knowledge of Cervical Cancer among Female Senior High School Students in the Tamale Metropolis of Ghana}

\author{
Der EM ${ }^{1}$, Yussif $\mathbf{R}^{2}$, Twumasi $\mathbf{I}^{2}$, Sijaabom $\mathbf{L}^{2}$ Azongo BT ${ }^{2}$ \\ 1. Department of Pathology, Yussif R School of Medicine and Health Sciences; University \\ for Development Studies, PO Box 1850, Tamale. \\ 2.Department of nursing, School of Allied Health Sciences; University for Development \\ Studies, PO Box 1850, Tamale
}

\section{ABSTRACT}

The lack of knowledge of cervical cancer and its risk factors have led to the late detection and poor prognosis of cervical cancer among women, especially in West Africa. This study seeks to assess the awareness, knowledge and the risk factors associated with cervical cancer among female Senior High School (SHS) students in the Tamale metropolis. A structured questionnaire was administered by the researchers to a total of 330 female students of four randomly selected SHSs in the Tamale Metropolis, Ghana. The questionnaire assessed students' knowledge and awareness of cervical cancer and its risk factors; it also gathered the demographic factors of the students. Approximately $79.1 \%(\mathrm{P}<0.001)$ of the students had ever heard of cervical cancer, $31.7 \%$ had knowledge about the signs and symptoms of the condition and only $24.6 \%$ were aware of the risk factors of cervical cancer. Teachers were the major source of information about cervical cancer for these students. Approximately, 37.9\% $(\mathrm{P}<0.001)$ of the respondents identified cervical cancer as a sexually transmitted infection. The majority $(79.1 \%$; $\mathrm{P}<0.001)$ of the respondents knew that cervical cancer was a preventable condition. A little over half of the students (53.9\%) were aware of cervical cancer screening methods but only $2.4 \%(\mathrm{P}<0.001)$ of the total respondents had ever been screened for cervical cancer. This study clearly shows the need to improve sexually active women's knowledge of cervical cancer risk factors, its signs and symptoms and preventive measures as well as how to assess available screening programme.

Keywords: Cervical cancer, risk factors, female students, Senior High School, Tamale, Northern Region 


\section{INTRODUCTION}

Cancer of the uteri cervix, although a preventable disease, is a common cause of cancerrelated morbidity and mortality in women in Ghana and worldwide. ${ }^{1,2,3,4}$ More than $85.0 \%$ of the women with cervical cancer are found to be living in developing countries, ${ }^{5}$ especially in Sub-Saharan Africa ${ }^{6}$, where the prevalence is found to be very high. ${ }^{7,8}$ Infection with the human Papilloma viruses (HPV), especially the high risk serotypes $(16,18)$, are found to account for $70 \%$ of cervical cancer cases in this geographical location. ${ }^{6,9}$ This is mainly due to the absence of population-based cervical cancer screening programme. ${ }^{10,11}$

Factors that are known to predispose individuals to cervical cancer include having multiple sexual partners (both males and females), multiparty, early onset of sexual intercourse, cigarette smoking, immunosuppression, long term use of oral contraceptives and co-infection with other sexually transmitted infections. ${ }^{12}$

Previous clinical and histopathological studies found that Ghanaian women with cervical cancer commonly present with an advanced stage of the disease to health facilities. ${ }^{7,13}$ Cervical cancer is diagnosed in relatively older women, the majority of whom are postmenopausal $^{13}$

In a study conducted in Southern Ghana, Ebu et al ${ }^{14}$ found low awareness levels of the disease among health workers. The awareness of a disease and its risk factors influence the health seeking behaviour of individuals. The lack of knowledge of cervical cancer and its risk factors may have contributed to the advanced stage of the disease at presentation in our health institutions. Cervical cancer has a long history of development from the infection with HPV to the development of invasive cancer. ${ }^{6,9,12}$

Students at the senior high school level constitute a great proportion of sexually active individuals in most countries and thus at risk of sexually-transmitted infections. . It is an accepted fact that once sexually active males and females are made aware of the disease and its associated risk factors, this will lead to a change in their health-seeking behavior and result in early detection and prevention of the condition. ${ }^{12}$ This study seeks to assess the knowledge and awareness of female Senior High School students in the Tamale metropolis about cervical cancer and its risk factors.

\section{MATERIALS AND METHOD}

\section{Study design:}

This was a descriptive cross-sectional study conducted among female Senior High School (SHS) students in the Tamale Metropolis.

\section{Site of study:}


Tamale Metropolis is one of the 26 districts in the Northern Region of Ghana. It is located in the central part of the region and shares boundaries with the Sagnarigu District to the West and North, Mion District to the East, and East Gonja to the South. The population of the Tamale Metropolis, according to the 2010 population and housing census, is 233,252. Females constitute $50.3 \%$ of this population. There are nineteen (19) Senior High Schools (SHSs) in the metropolis of which ten (10) are public and nine (9) are private schools.

\section{Study Population:}

This study was conducted among female students offering General Arts and General Science in four (4) randomly selected public Senior High Schools in the Tamale Metropolis.

\section{Sampling methods:}

Probability sampling was used with emphasis on stratified sampling method.

\section{Sample Size estimation:}

The four (4) selected public SHSs of the Tamale metropolis were Tamale SHS, Ghana SHS, Tamale Girls SHS and Vitting SHS/Technical. These schools had a female population of 720, 562, 904 and 281 respectively. Using $22.5 \%$ prevalence rate of cervical cancer in Sub-Sahara Africa a sample size of 268 was calculated. A maximum sample size of 300 was proposed to be collected in the study. The sample size was calculated using the Cochran formula below at $95 \%$ confidence level and $5 \%$ margin of error.

$$
\mathrm{N}=\mathrm{t}^{2} \times \mathrm{p}(1-\mathrm{p}) / \mathrm{m}^{2}
$$

Where:

$\mathrm{N}=$ required sample size

$\mathrm{t}=$ confidence level at $95 \%$ (standard value of 1.96 )

$\mathrm{p}=$ estimated prevalence of cervical cancer in Sub Saharan Africa.

$\mathrm{m}=$ margin of error at $5 \%$ (standard valve of 0.05 )

\section{Data collection and analysis:}

A structured questionnaire with multiple choices was administered to randomly select female students of selected SHSs by the researchers to obtain information on cervical cancer. The questionnaire was designed based on the study objectives and a review of previous studies from the literature on cervical cancer. The questionnaire was divided into 2 main parts. The first part dealt with the socio-demographic profile of the subjects (eg. age, sex, education, etc.) and the second part consisted of questions regarding the knowledge, signs and symptoms, risk factors and available methods for cervical cancer screening. Data obtained were entered into SPSS software version 23.0 and cross checked to prevent double entries. Data were analyzed for mean and standard deviation and presented in frequency tables. Associations between variables were determined using Fisher's exact test. 


\section{RESULTS AND DISCUSSION}

\section{Socio-demographic characteristics of respondents}

The ages of the participants ranged from 13 to 21 years with a mean age of 17.0 years (SD \pm 1.2 ) and a modal age group of $16-18$ years. A greater proportion of the students were Muslims $(230,69.7 \%$; $\mathrm{P}<0.001)$. Also, a great majority of the participants were single and have never been married $(316,95.8 \%$; $\mathrm{P}<0.001)$ (Table 1).

Table 1: Socio-demographic characteristics of respondents

\begin{tabular}{llll}
\hline Variables & Frequency(n) & Percentage (\%) & P-value \\
\hline Age (years) & 31 & & \\
$13-15$ & 274 & 9.4 & \\
$16-18$ & 25 & 83.0 & \\
$19-21$ & 330 & 100.0 & \\
Total & & & \\
Religion & 99 & 30.0 & $<0.001$ \\
Christian & 230 & 69.7 & \\
Muslim & 1 & 0.3 & \\
Traditionalist & 330 & 100.0 & \\
Total & & & \\
Name of School & 89 & 27.0 & \\
Ghana Senior High School & 92 & 27.9 & \\
Vitting Senior High/Technical School & 90 & 27.3 & \\
Tamale Girls Senior High School & 59 & 17.9 & \\
Tamale Senior High School & 330 & 100.0 & \\
Total & & & \\
Year of study & 149 & 45.2 & \\
First year & 181 & 54.8 & \\
Second year & 330 & 100.0 & \\
Total & & & \\
Programme of study & 164 & 49.7 & \\
General Art & 166 & 50.3 & \\
Science(General Science/Home Economics) & 100.0 & \\
Total & 330 & 95.8 & \\
Marital Status & & 2.4 & \\
Single & 316 & 1.8 & \\
Married & 8 & $\mathbf{1 0 0 . 0}$ & \\
Cohabitating & 6 & & \\
Total & 330 & & \\
\hline
\end{tabular}

In Ghana, health sector workers and women attending antenatal clinics (ANC) have been the focus of studies assessing the knowledge and awareness of cervical cancer as a disease condition and its associated risk factors. ${ }^{14,15}$ The current study is different because it was conducted among young sexually active female SHS students. The age distribution is however very similar to the pattern reported in Saha et al ${ }^{16}$ study conducted among college students in India, a developing country like Ghana.

General knowledge about cervical cancer 
A total of 261 students $(79.1 \%, \mathrm{P}<0.001)$ had heard of cervical cancer. Of this number, 164 (62.8\%, $\mathrm{P}<0.001)$ obtained the information from their teachers as part of an integrated science course. The great majority of the students did not know that cervical cancer was sexually transmitted $(205,62.1 \% ; \mathrm{P}<0.001)$. Many of the respondents $(79.1 \%, \mathrm{P}<0.001)$ identified cervical cancer as a preventable disease (Table 2).

Table 2: General knowledge/awareness of cervical cancer

\begin{tabular}{llll}
\hline Variables & $\begin{array}{l}\text { Frequency } \\
\text { (n) }\end{array}$ & $\begin{array}{l}\text { Percentage } \\
(\boldsymbol{\%})\end{array}$ & P-value \\
\hline Have you ever heard of cervical cancer? & 261 & 79.1 & $<0.001$ \\
Yes & 69 & 20.9 & \\
No & 164 & 62.8 & $<0.002$ \\
What is your source of information? & 97 & 37.2 & \\
Teacher/class room & & & \\
Others & 88 & 53.7 & \\
Under which subject was it taught? & 29 & 17.7 & \\
Integrated Science & 8 & 4.9 & \\
Social Studies & 17 & 10.4 & \\
Management in living & 22 & 13.3 & \\
Biology & & & \\
Don't know & 125 & 37.9 & \\
Is cervical cancer a sexually transmitted infection? & & 62.1 & \\
Yes & 205 & & \\
No & & 79.1 & \\
Is cervical cancer preventable? & 261 & $\mathbf{2 0 . 9}$ & \\
Yes & $\mathbf{6 9}$ & \\
No & &
\end{tabular}

In the present study, the awareness of cervical cancer among respondents was very high (79.1\%; $\mathrm{P}<0.001)$. The level of awareness of the disease in this current study is comparable to those reported by Kamzol et al in Krakow, Poland, ${ }^{17}$ Bansal et al in Bhopal, India ${ }^{18}$ and Shrestha et al in Nepal ${ }^{19}$. However, high awareness in the current study differs from those reported by Ebu et $\mathrm{al}^{14}$ and Opoku et $\mathrm{al}^{15}$ in southern and northern Ghana respectively, which found low levels of awareness of cervical cancer among health workers and pregnant women attending antennal clinics. Although this may not be a good point of comparison based on the target groups of the two previous studies cited above, the most likely reason for the high level of awareness of cervical cancer in this current study is the fact that information on cervical cancer was part of the integrated science course taught in SHSs, with the teachers being the main source of information.

This study found that a significant number of the respondents $(62.1 \% ; \mathrm{P}<0.001)$ correctly identified cervical cancer as a sexually transmitted infection. This finding supports previous studies conducted among college students in Ghana ${ }^{20}$, and Pakistan. ${ }^{21}$ 


\section{Risk factors of cervical cancer}

The study found a significant lack of knowledge of the risk factors of cervical cancer among the students for all the factors provided $(\mathrm{P}<0.001)$ (Table 3). For instance, only $39.1 \%$ were aware that having multiple sexual partners was a risk factor, whilst only $27.9 \%$ mentioned early sexual intercourse as a risk factor (Table 3).

Table 3: Risk factors of cervical cancer

\begin{tabular}{|c|c|c|c|}
\hline Variables & Frequency (n) & Percentage (\%) & P-value \\
\hline \multicolumn{4}{|l|}{ Early onset of sexual intercourse } \\
\hline Yes & 92 & 27.9 & $<0.001$ \\
\hline No & 238 & 72,1 & \\
\hline \multicolumn{4}{|c|}{$\begin{array}{l}\text { Infection with sexually transmitted } \\
\text { virus }\end{array}$} \\
\hline Yes & 125 & 37.9 & $<0.001$ \\
\hline No & 205 & 62.1 & \\
\hline \multicolumn{4}{|l|}{ Smoking of cigarette/tobacco } \\
\hline Yes & 112 & 33.9 & $<0.001$ \\
\hline No & 218 & 66.1 & \\
\hline \multicolumn{4}{|c|}{$\begin{array}{l}\text { Having a weakened immune system } \\
\text { (e.g. HIV) }\end{array}$} \\
\hline Yes & 113 & 34.2 & $<0.001$ \\
\hline No & 217 & 65.8 & \\
\hline \multicolumn{4}{|l|}{ Long term use of contraceptives } \\
\hline Yes & 114 & 34.5 & $<0.001$ \\
\hline No & 216 & 65.5 & \\
\hline \multicolumn{4}{|c|}{$\begin{array}{l}\text { Multiple sexual partners ( females and } \\
\text { males) }\end{array}$} \\
\hline Yes & 129 & 39.1 & $<0.001$ \\
\hline No & 201 & 60.1 & \\
\hline \multicolumn{4}{|l|}{ Polygamous marriage } \\
\hline Yes & 63 & 19.1 & $<0.001$ \\
\hline No & 267 & 80.9 & \\
\hline \multicolumn{4}{|c|}{$\begin{array}{l}\text { Age of women at risk of cervical } \\
\text { cancer }\end{array}$} \\
\hline Women aged $13-49$ years & 43 & 13.0 & \\
\hline Women aged 50 years and above & 24 & 7.3 & $<0.001$ \\
\hline Don't know & 263 & 79.7 & \\
\hline
\end{tabular}

The current study revealed that only $24.3 \%$ of the respondents knew at least one risk factor of

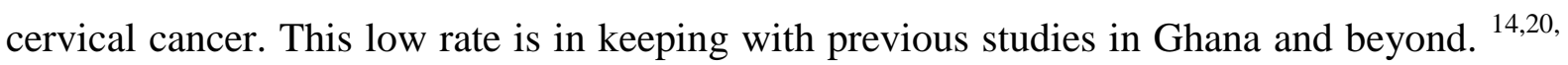
${ }^{22}$ The awareness about the risk factors and symptoms of cervical cancer have been found to be limited in most sub-Saharan African countries including Kenya, Zimbabwe, Cameroon and Nigeria. ${ }^{23,24,25,26}$ The risk factors identified by respondents in descending order were: multiple sexual partners, infection with sexually transmitted virus, long term use of contraceptives and having a weak immune system. Although the knowledge of respondents on the risk factors of cervical cancer was low, the spectrum of risk factors correctly identified 
is in keeping with findings of other studies across the globe. ${ }^{27,28,29}$ The current study found that the majority of the respondents $(79.1 \%$; $\mathrm{P}<0.001)$ were aware that cervical cancer can be prevented. This was a very significant finding and supports the study by Getahun in Ethiopia 30

\section{Signs and symptoms of cervical cancer}

When provided with a list of signs and symptoms to choose from, the knowledge of the students on the common signs and symptoms of cervical cancer closely mirrored that of their knowledge and awareness of the risk factors (Table 4). The following were identified as signs and symptoms of cervical cancer in descending order: persistent vaginal discharge with unpleasant smell (43.3\%), persistent pelvic pain (37.3\%), vaginal bleeding during or after sexual intercourse (29.7\%) and abnormal menstrual cycle (27.9\%) (Table 4).

\section{Table 4: Signs and symptoms of cervical cancer}

\begin{tabular}{|c|c|c|c|}
\hline Variables & $\begin{array}{l}\text { Frequency } \\
\text { (n) }\end{array}$ & $\begin{array}{l}\text { Percentage } \\
(\%)\end{array}$ & P-value \\
\hline \multicolumn{4}{|c|}{ Is inter menstrual bleeding a symptom of cervical cancer? } \\
\hline Yes & 75 & 22.7 & $<0.001$ \\
\hline No & 255 & 77.3 & \\
\hline \multicolumn{4}{|c|}{ Is heavy and prolonged vaginam bleeding a symptom of cervical cancer? } \\
\hline Yes & 92 & 27.9 & $<0.001$ \\
\hline No & 238 & 72.1 & \\
\hline \multicolumn{4}{|c|}{ Is vaginal bleeding after menopause a symptom of cervical cancer? } \\
\hline Yes & 129 & 39.1 & $<0.001$ \\
\hline No & 201 & 60.9 & \\
\hline \multicolumn{4}{|c|}{ Is vaginal bleeding during or after sex a sign of cervical cancer? } \\
\hline Yes & 98 & 29.7 & $<0.001$ \\
\hline No & 232 & 70.3 & \\
\hline \multicolumn{4}{|c|}{ Is persistent offensive vaginal discharge a symptom of cervical cancer? } \\
\hline Yes & 143 & 43.3 & $<0.008$ \\
\hline No & 187 & 56.7 & \\
\hline \multicolumn{4}{|c|}{ Is persistent pelvic pain a symptom of cervical cancer? } \\
\hline Yes & 123 & 37.3 & $<0.001$ \\
\hline No & 207 & 62.7 & \\
\hline \multicolumn{4}{|c|}{ Is persistent lower back pain a symptom of cervical cancer? } \\
\hline Yes & 48 & 14.5 & $<0.001$ \\
\hline No & 282 & 85.5 & \\
\hline \multicolumn{4}{|c|}{ Is unexplained weight loss a sign of cervical cancer? } \\
\hline Yes & 74 & 22.4 & $<0.001$ \\
\hline No & 256 & 77.6 & \\
\hline
\end{tabular}

The knowledge of the students on the signs and symptoms of cervical cancer was low (31.7\%). The signs and symptoms of cervical cancer identified by respondents in this study in descending order were: persistent vaginal discharge with unpleasant smell, persistent pelvic pain and vaginal bleeding during or after sexual intercourse. Although the spectrum of signs and symptoms identified by respondents is in line with the study by Ahmed et al in 
Nigeria $^{31}$ and the systematic review by Shapley et al on the risk factors of cervical cancer, ${ }^{32}$ it however, differs from studies conducted among health professionals, predominantly nurses, in India, Asia and Niger where knowledge on the signs and symptoms of cervical cancer was found to be adequate ${ }^{33,34,35}$ The reason for the disparity in these studies may be attributed to the fact that previous studies on this topic were conducted among health professionals who are likely to have had foreknowledge of this condition.

\section{Awareness of the preventive methods of cervical cancer}

Many of the respondents $(190,53.9 \%$; $\mathrm{P}<0.001)$ were aware of the availability of cervical cancer screening services in Tamale. Of this number, less than $40.0 \%$ indicated that routine cervical cancer screening will ensure early detection and prevention of the condition. The great majority of those who had heard of screening programmes never took the advantage to avail themselves of the service $(192,95.8 \%$; $\mathrm{P}<0.001)$. Of the 8 girls who have ever had the screening done, five $(\mathrm{P}=0.693)$ said the screening was performed free of charge (Table 5).

A significant number of the respondents were aware of cervical cancer screening services, the location and the associated health benefits to women. This finding is comparable with studies from Nigeria ${ }^{31,36}$, but differs from other studies that found very low awareness levels $(16.0 \%$ to $19.7 \%$ ) of the availability of screening services among respondents interviewed. ${ }^{37,38}$

Table 5: Availability and utilization of cervical screening methods

\begin{tabular}{llll}
\hline & $\begin{array}{l}\text { Frequency } \\
(\mathbf{n})\end{array}$ & $\begin{array}{l}\text { Percentage } \\
(\boldsymbol{\%})\end{array}$ & $\begin{array}{l}\text { P- } \\
\text { value }\end{array}$ \\
\hline $\begin{array}{l}\text { Do you know any screening centre? } \\
\text { Yes }\end{array}$ & 190 & 57.6 & $<0.001$ \\
No & 140 & 42.4 & \\
Total & & & \\
$\begin{array}{l}\text { Is screening important in early detection of the } \\
\text { disease? }\end{array}$ & 76 & 40.0 & $<0.001$ \\
Yes & 114 & 60.0 & \\
No & & & \\
Have you been screened for cervical cancer before? & 8 & 4.2 & $<0.001$ \\
Yes & 182 & 95.8 & \\
No & & & \\
Total & & & \\
Was the screening free of charge? & 5 & 62.5 & 0.693 \\
Yes & 3 & 37.5 & \\
No & & \\
\hline
\end{tabular}

\section{Limitations}

1. The parental background/occupation of respondents were not taken into consideration in the design of the structured questionnaire.

2. There was recalled bias among respondents.

\section{Recommendations}


Population based cervical screening is recommended in all the health facilities in Ghana. This will enable early detection of precancerous lesions and treatment.

The government and the ministry of health should provide training courses on cervical cancer screening for midwifes in selected health facilities throughout the country, who at the end of the training would act as trainers of trainee.

Wide and effective dissemination of awareness about the disease among women must form an integral part of public health policy of government.

\section{CONCLUSION:}

The study found that majority of the students has heard of cervical cancer from teachers. A little above half were aware of the availability of cervical cancer screening services in Tamale. However, a significant number of the students lack knowledge on the mode of transmission, the risk factors and the symptoms of cervical cancer.

\section{DECLARATIONS}

\section{Ethical consideration}

Permission to conduct the study was obtained from the ethical committee of school authority. Written as well as verbal assurances were given to the respondents to withdraw from the study at any time they wished. Also, the respondents were assured of anonymity and confidentiality of information entrusted. Cultural values, norms and beliefs of respondents were duly respected and observed.

\section{Consent for publication.}

All the authors read and agreed for the manuscript to be published.

\section{Availability of data and material}

The data used to write this manuscript will be made available on request.

\section{Competing interest}

The authors declare no competing interests

\section{Funding}

The authors received no funding for the work

\section{Authors' contributions}

EMD, RY, TI and SL conceptualized the study. RY, TI and SL compiled and entered the data. EMD, RY,TI and SL analysed the data. EMD, RY, TI and SL drafted the manuscript. EMD, RY, TI,SL and TBA read, edited and approved the final manuscript.

\section{REFERENCES}

1. Der EM, Kwame-Aryee RA, Tettey Y, Seffah JD, Wiredu EK, Adu Bonsaffour K. et al (2015) Malignant Tumours of the Female Genital Tract: A 10-Year 
Histopathological Review at the Korle-Bu Teaching Hospital (2002-2011). J Clin Exp Oncol. 2015;4:4. doi:http://dx.doi.org/10.4172/2324-9110.1000146

2. Wiredu EK, Armah HB Cancer mortality patterns in Ghana: a 10-year review of autopsies and hospital mortality BMC Public Health 2006;6:159. DOI: 10.1186/14712458-6-159

3. Jemal A, Bray F, Center MM, Ferlay J, Ward E, Forman D. Global Cancer Statistics. CA Cancer Journal Clin. 2011; 61: 69-90.

4. Wittet S, Tsu V. Cervical Cancer Prevention and the Millennium development goals. Bulletin of the World Health Organisation. 2008; 86:44-491.

5. Ferlay J, Shin HR, Bray F, Forman D, Mathers C, Parkin DM. Estimates of worldwide burden of cancer in 2008: GLOBOCAN 2008. International Journal of Cancer. 2010; 127:2893-2917.

6. Denny L, Anorlu R. Cervical cancer in Africa. Cancer Epidermiol Biomarkers. 2012;21:1434-1438

7. Nkyekyer. Pattern of gynaecological cancers in Ghana. East Afr Med J. 2000;77:534538

8. Denny L, Adewole I, Anorlu R, Dreyer R, Moodley M, Smith T, et al. Human papillomavirus prevalence and type distribution in invasive cervical cancer in subSaharan Africa. International journal of cancer 2014;134: 1389-1398.

9. GLOBOCANIARC, Cancer epidermiology, cancer registries, statistics, genetics, P53, Globocan, incidence, mortality. 2012.

10. Sankaranarayanan R, Budukh AM, Rajkumar R. Effective screening programmes for cervical cancer in low- and middle-income developing countries. Bull WHO, Suppl. 2001;79:954-962.

11. Anderson GH, Boyes DA, Benedet JL, Le Riche JC, Matisic JP, Suen KH, et al. Organization and results of the cervical cytology screening programme in British Columbia, 1955-85. BMJ 1988;296:975-978.

12. American Cancer Society (ACS), American Society for Colposcopy and Cervical Pathology (ASCCP), American Society for Clinical Pathology (ASCP). Cervical cancer screening guideline for average-risk women; 2012.

13. Der EM, Adu-Bonsaffoh K, Tettey Y, Kwame-Aryee RA, Saffah JD, Alidu H, et al. Clinical-pathological Characteristics of Cervical Cancer in Ghanaian Women. JMBS $2014 ; 3: 27-32$. 
14. Ebu NI, Mupepi SC, Siekwa MP, sampselle CM. Knowledge, practice and barrier toward cervical cancer screening in Elmina, Southern Ghana. International Journal of Women's Health. 2015; 31-39

15. Opoku AC, Laryea Nii EB, Spangenberg K, Cheryl M, Kolbilla D, Gold JK. Perception and risk factors for cervical cancer among women in northern Ghana. Ghana Med J. 2016; 50: 84-89.

16. Saha A, Chaudhury AN, Bhowmik P, Chatterjee R. Awareness of cervical cancer among female students of premier colleges in Kolkata, India. Asian Pac J Cancer Prev. 2010;11:1085-90.

17. Kamzol W, Jaglarz K, Tomaszewski KA, Puskulluoglu M, Krezemieniecki K.. Assessment of knowledge about cervical cancer and its prevention among female students aged 17-26 years. Eur J Obster Gynecol Reprod Biol, 2012;166:196-203.

18. Bansal AB, Pakhare AP, Kapoor N, Mehrotra R, Kokane AM. Knowledge, attitude, and practices related to cervical cancer among adult women: A hospital-based crosssectional study. J Nat Sc Biol Med 2015;6:324-328.

19. ShresthaJ, Saha R, Tripathi N. Knowledge, attitude and practice regarding cervical cancer screening amongst women visiting tertiary centre in Kathmandu, Nepal. Nepal J Med Sci 2013;2:85-90.

20. Abotchie NP, Shokar KN. Cervical Cancer Screening Among College Students in Ghana: Knowledge and Health Beliefs. Int J Gynecol Cancer. 2009; 19: 412-416. doi: 10.1111/IGC.0b013e3181a1d6de

21. Syed FA, Samia A, Nauman FM, Sidra A, Muneeza A, Nida A, et al. Knowledge and awareness about Cervical Cancer and its prevention amongst Interns and Nursing Staff in Tertiary Care Hospitals in Karachi, Pakistan. PLoS One. 2010; 5: e11059.

22. Ziba F. A, Baffoe P, Dapare PPM, S. O. Shittu SO, Antuamwine BB. Awareness and knowledge level of cervical cancer among women of reproductive age in Bolgatanga municipality. JMBS 2015; 4: 1-6

23. Hyacinth HI, Adekeye OA, Ibeh JN, Osoba T. Cervical cancer and pap smear awareness and utilization of pap smear test among Federal civil servants in North Central Nigeria. PLoS One, 2012; 7: e46583.

24. Mupepi SC, Sampselle CM,Johnson TR. Knowledge, attitudes and demographic factors influencing cervical cancer screening behavior of Zimbabwean women. Journal of Women's Health 2011;20:943 - 952.

25. Gichangi P, Estambale B, Bwayo J, Rogo K, Ojwang S, Opiyo A, et al Knowledge and practice about cervical cancer and Pap smear testing among patients at Kenyatta 
National Hospital, Nairobi, Kenya. International Journal of Gynecological Cancer; 13:827-833.

26. Ttebeu, P.-M., Mmajor , A.L., Rrapiti E, e., Ppetignat P, p., Bbouchardy C, c., Ssando Z. et al. The attitude and knowledge of cervical cancer by Cameroonian women; a clinical survey conducted in Maroua, the capital of Far North Province of Cameroon. International journal of Gynecological Cancer, 2008; 18: 761-765.

27. Louie KS, de Sanjose S, Diaz M, Castellsagué X, Herrero R , C J Meijer, CJ. Et al. Early age at first sexual intercourse and early pregnancy are risk factors for cervical cancer in developing countries. Bristish Journal of Cancer, 2009; 100: 1191-1197.

28. Castellsague X, Munoz N: Cofactors in human papillomavirus carcinogenesis-role of parity, oral contraceptives, and tobacco smoking. Journal of National Cancer Institute, 2003;31:20-28.

29. Sanjose S. The epidemiology of human papilloma virus infection and the cervical cancer. Disease markers, 2007;213 - 227.

30. Getahun F, Mazengia F, Abuhay M, Birhanu Z. Comprehensive knowledge about cervical cancer is low among women in Northwest Ethiopia. BMC Cancer, 2013; 13: 2.

31. Ahmed SA, Sabitu K, Idris SH, Ahmed R. Knowledge, attitude and practice of cervical cancer screening among market women in Zaria, Nigeria. Niger Med J. 2013;54:316-319. doi:10.4103/0300-1652.122337

32. Shapley M, Jordan J, Croft PR. A systematic review of post-coital bleeding and risk of cervical cancer. Br J Gen Pract. 2006;56:453-460.

33. Shah V, Vyas S, Shrivastava M. Awareness and knowledge of cervical cancer and its prevention among the nursing staff of a Tertiary Health Institute in Ahmedabad, Gujarat, India. Ecancermedicals science, 2012, 6:270.

34. Nganwai P, Truadpon P, Inpa C, Sangpetngam B, Mekjarasnapa M, Apirakarn M, et al. Knowledge, attitudes and practices vis-a-vis cervical cancer among registered nurses at the faculty of medicine, Khonkaen University, Thailand. Asia Pac. J. Cancer Prev, 2008; 9:15-18.

35. Anya SE, Oshi DC, Nwosu SO, Anya AE. Knowledge, attitude and practice of female health professionals regarding cervical cancer and pap smear. Niger J. Med, 2005;14: 283-286.

36. Aboyeji PO. Knowledge, attitude and practice of cervical smear as a screening procedure for cervical cancer in Ilorin, Nigeria. Trop J Obstet Gynae. 2004; 21:114117. 
37. Ezem BU. Awareness and uptake of cervical cancer screening in Owerri, SouthEastern Nigeria. Ann Afr Med. 2007; 6:94-98.

38. Feyi-Waboso PA, Kamanu C, Aluka C. Awareness and risk factors for cervical cancer among women in Aba, south-eastern Nigeria. Trop J Obstet Gynae, 2005; 22: 25-26.

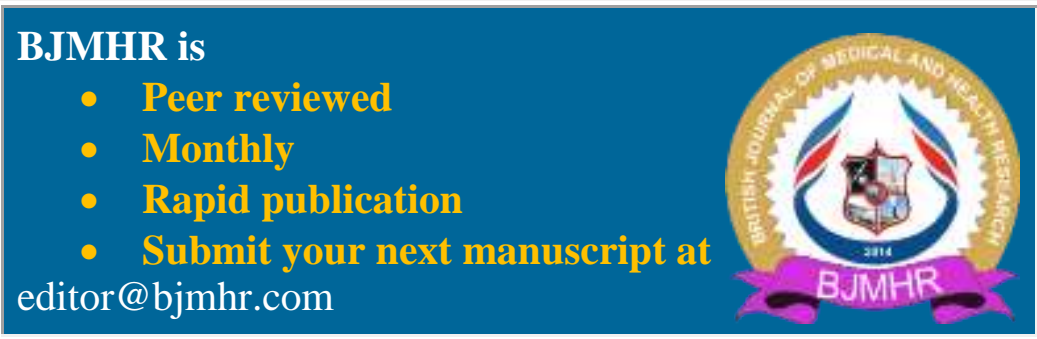

